\title{
太湖悬浮颗粒物细菌碱性磷酸酶编码基因的分布特征”
}

\author{
章婷䂀 ${ }^{1,2,3}$, 卢小然 ${ }^{1}$, 魏 超 ${ }^{1}$, 李德芳 ${ }^{1}$, 秦梦瑶 ${ }^{1}$, 张利民 ${ }^{1 * *}$ \\ (1: 南京师范大学环境学院,南京 210023) \\ ( 2 : 江苏省地理信息资源开发与利用协同创新中心, 南京 210023) \\ (3: 江苏省物质循环与污染控制实验室, 南京 210023)
}

\begin{abstract}
摘 要: 颗粒态有机磷的碱性磷酸酶矿化是水生态系统磷循环的重要环节, 对细菌碱性磷酸酶编码基因的解析有利于揭 示浅水富营养化湖泊有机磷矿化的微生物驱动机制. 本文以太湖不同生态类型湖区悬浮颗粒物为研究对象, 运用苂光定 量 PCR 技术, 探究太湖水体中悬浮颗粒物细菌碱性磷酸酶 $p h o X$ 和 $p h o D$ 基因的时空分布特征, 以及影响两类基因丰度的 主要环境因子. 结果表明: 太湖不同生态类型湖区中 $p h o D$ 基因丰度是 $p h o X$ 基因的 $6 \sim 42$ 倍, 且二者均存在显著的时空分 布差异. 6 月, 河口区 $p h o X\left(9.18 \times 10^{4}\right.$ copies/L $)$ 和 $p h o D\left(1.88 \times 10^{6} \mathrm{copies} / \mathrm{L}\right)$ 基因丰度均最高, 其次分别为草型区、湖心区 和藻型区. 与 6 月相比, 9 月各湖区 $p h o D$ 基因丰度显著降低, 而 $p h o X$ 基因丰度在藻型区和草型区则有所升高. 9 月, 草型 区 $p h o X$ 基因丰度最高 $\left(5.70 \times 10^{4} \mathrm{copies} / \mathrm{L}\right)$, 河口区最低 $\left(1.49 \times 10^{4} \mathrm{copies} / \mathrm{L}\right)$. 水生植物对 $p h o X$ 和 $p h o D$ 基因丰度具有重 要贡献. 悬浮颗粒物细菌 $p h o X$ 基因丰度可能被低估. 溶解氧、总氮和总磷是影响太湖 $p h o X$ 和 $p h o D$ 基因丰度的主要环境 因子.
\end{abstract}

关键词: 碱性磷酸酶; 编码基因; 悬浮颗粒物; 太湖; qPCR

\section{Spatial and temporal distribution of alkaline phosphatase encoding genes in suspended particulates in Lake Taihu}

\author{
ZHANG Tingxi ${ }^{1,2,3}$, LU Xiaoran ${ }^{1}$, WEI Chao ${ }^{1}$, LI Defang ${ }^{1}$, QIN Mengyao ${ }^{1}$ \& ZHANG Limin $^{1 * *}$ \\ (1: School of Environment, Nanjing Normal University, Nanjing 210023, P.R.China) \\ (2: Jiangsu Center for Collaborative Innovation in Geographical Information Resource Development and Application, Nanjing \\ 210023, P.R.China) \\ (3: Jiangsu Key Laboratory of Material Cycle \& Pollution Control, Nanjing 210023, P.R. China)
}

\begin{abstract}
The mineralization of organic $\mathrm{P}$ to orthophosphate in suspended particles by alkaline phosphatase plays an important role in phosphorus cycling in aquatic ecosystem, especially in shallow lake. The study on bacterial alkaline phosphatase-encoding genes is of great significance to reveal the microbial driving mechanisms of organic P mineralization. We identified the spatial and temporal distribution characteristics of the abundance of $p h o X$ and $p h o D$ genes in suspended particles in four ecological regions in Lake Taihu, a large shallow eutrophic lake, and explored the main environmental factors affecting the abundance of the two genes. The qPCR analysis suggested that $p h o D$ gene abundance was 6-42 times higher than $p h o X$ gene abundance in four ecological regions in the study period, and both of $p h o D$ and $p h o X$ genes abundance in suspended particles has significant difference in spatial and temporal distribution. The highest abundance of $p h o X\left(9.18 \times 10^{4}\right.$ copies/L) and $p h o D\left(1.88 \times 10^{6}\right.$ copies/L) were found in the river estuaries in June, followed by that in macrophyte-dominated zone, central lake zone and algae-dominated zone. Compared with the genes abundances in June, the abundance of $p h o D$ gene in four ecological regions decreased significantly in September while $p h o X$ gene abundance increased in algae-dominated zone and macrophyte-dominated zone. In September, the abundance of $p h o X$ gene $\left(5.70 \times 10^{4}\right.$ copies/L) in macrophyte-dominated zone was the highest and the lowest was in the river estuaries $\left(1.49 \times 10^{4}\right.$ copies/ L). Macrophytes play an important role in determining the abundance of $p h o D$ and $p h o X$ genes. The abundance of $p h o X$ genes in
\end{abstract}

* 国家水体污染控制与治理科技重大专项 (2017ZX07202-004) 和国家自然科学基金项目 $(41303058,41877336$ ) 联合资 助. 2018-08-26 收稿;2019-02-20 收修改稿. 章婷䂀( 1975 ), 女,博士, 副教授;E-mail :zhangtingxi@ njnu.edu.cn.

** 通信作者;E-mail:lmzhang@ njnu.edu.cn. 
suspended particles may be underestimated. Dissolved oxygen, total nitrogen and total phosphorus are the main environmental factors affecting the abundance of bacterial $p h o X$ and $p h o D$ genes in suspended particulates.

Keywords: Alkaline phosphatase; encoding gene; suspended particles; Lake Taihu; qPCR

磷是淡水初级生产力的关键限制性营养元素, 对湖泊蓝藻水华具有重要影响 ${ }^{[1]}$. 对欧洲和北美大量湖 泊生态系统长期的研究表明,控制蓝藻水华取决于减少单一营养盐—— “磷”的输人 ${ }^{[2]}$. 湖泊生态系统中磷 的主要来源为外源磷的输人和内源磷 (悬浮颗粒物和沉积物) 的释放. 在控制外源磷输人的情况下, 内源磷 的释放使得富营养化水体通常需要 $10 \sim 15$ 年才能对总磷负荷的减少做出反应 ${ }^{[3]}$, 有些湖泊甚至需要 20 年 以上 ${ }^{[4]}$.

湖泊水体中颗粒物的产生、沉积和再悬浮过程以及颗粒物的高反应性, 使得颗粒物在化学物质的迁移、 循环和可利用性上起到关键的作用,成为连接水体、沉积物和食物链之间化学组分的重要纽带 ${ }^{[5]}$. 颗粒态磷 是水体中磷的主要存在形式, 我国近海水体颗粒态磷占到总磷的 $50 \%$ 以上 ${ }^{[6]}$, 滇池水体可达 $70 \%{ }^{[7]}$, 长江水 体达到 $80 \%{ }^{[8]}$, 太湖梅梁湾水体甚至达到 $90 \%$ 以上 ${ }^{[9]}$, 日本第二大浅水湖泊 Lake Kasumigaura 水体达到 $42.5 \%{ }^{[10]}$. 而有机磷是颗粒态磷的重要组成部分, 太湖水体颗粒态有机磷占颗粒态总磷的 $87.5 \% \sim 100 \%{ }^{[11]}$; 北太平洋表层水体颗粒态有机磷占颗粒态总磷 $80 \%$ 以上 ${ }^{[12]}$; Lake Kasumigaura 水体颗粒态有机磷占 $\mathrm{NaOH}-$ EDTA 可提取颗粒态总磷的 $63.4 \%^{[10]}$.

颗粒态有机磷的矿化分解是维持湖泊初级生产力的重要过程. 细菌是有机磷的重要矿化者 ${ }^{[13-14]}$, 它通 过分泌磷酸酶, 将有机磷矿化为正磷酸盐, 参与磷的生物地球化学循环 ${ }^{[15-16]}$, 维持湖泊富营养化状态. 迄今 为止, 对湖泊细菌碱性磷酸酶的研究还多处于关注其胞外总活性及其与环境因素关系的层面 ${ }^{[17-20]}$, 缺乏对 细菌碱性磷酸酶更为深人的认识. 以碱性磷酸酶编码基因为标记物, 可进一步加深对有机磷微生物矿化机 制的探究. 细菌碱性磷酸酶编码基因主要分为 $p h o A 、 p h o D$ 和 $p h o X 3$ 种类型. 目前在海洋和土壤生态系统, 对 细菌碱性磷酸酶编码基因已经开展了大量的研究工作, 包括编码基因丰度及多样性 ${ }^{[21-23]}$ 、功能细菌分 布 ${ }^{[21,24-26]}$ 及影响因素 ${ }^{[25,27-31]}$ 等. 相比海洋生态系统, 在同样受磷限制的湖泊生态系统中, 碱性磷酸酶编码基 因的研究还比较匮乏 ${ }^{[32-34]}$, 进而对微生物矿化有机磷的机制缺乏了解. 目前, 湖泊悬浮颗粒物细菌碱性磷酸 酶编码基因类型及分布还未见报道.

太湖是我国典型富营养化浅水湖泊,颗粒态有机磷矿化率相对较高 ${ }^{[35]}$. 本文以太湖不同生态类型湖区 悬浮颗粒物为研究对象, 解析太湖悬浮颗粒物细菌碱性磷酸酶编码基因类型、时空分布特征及影响因素. 研 究结果对进一步揭示湖泊有机磷矿化的微生物驱动机制具有重要意义.

\section{1 研究区域}

太湖 $\left(30^{\circ} 55^{\prime} 40^{\prime \prime} \sim 31^{\circ} 32^{\prime} 58^{\prime \prime} \mathrm{N}, 119^{\circ} 52^{\prime} 32^{\prime \prime} \sim 120^{\circ} 36^{\prime} 10^{\prime \prime} \mathrm{E}\right.$ ) 是我国第 3 大淡水湖泊, 水域面积 $2338 \mathrm{~km}^{2}$, 平 均水深 $1.89 \mathrm{~m}$, 南北长 $68.5 \mathrm{~km}$, 东西宽 $56.0 \mathrm{~km}$, 是典型的浅水湖泊, 位于中国工业化程度最高的长江三角洲 地区. 太湖湖区生境多样, 根据水体营养状态 ${ }^{[36]}$ 、水环境特征 ${ }^{[37]}$ 及初级生产力水平 ${ }^{[38-39]}$, 本研究选取 4 类生 态类型湖区, 设置 6 个采样点, 分别是藻型湖区梅梁湾 (ML)、湖心区 ( L1、L2)、河口区 ( R1 位于洪巷港, R2 位于陈东港) 和草型湖区贡湖湾 $(\mathrm{GH})$. 采样点位分布见图 1.

梅梁湾为藻型湖区, 透明度较低, 是目前太湖蓝藻水华暴发严重的湖区. 贡湖湾采样点位于水生植物分 布区, 透明度高. 湖心区受风浪扰动较大, 北部太湖的湖心区 ( L2) 相对于 L1 来说, 与各个水域的交换紧密, 受西北湖区、贡湖湾及南部湖区的影响较大 ${ }^{[40]}$. 河口区长期接纳农业化学品、土壤颗粒、工业废水等, 水质 较差.

\section{2 材料与方法}

\section{1 样品的采集与预处理}

2017 年 6 月和 9 月进行两次野外采样. 现场测定水体 $\mathrm{pH}$ 、溶解氧 ( DO ) 、水温 ( Temp)、氧化还原电位 (Eh) 和水体透明度. 在各采样点, 使用采水器采集 3 份表层 (约水面下 $50 \mathrm{~cm}$ ) 水样, 置于预先酸洗过的 $30 \mathrm{~L}$ 


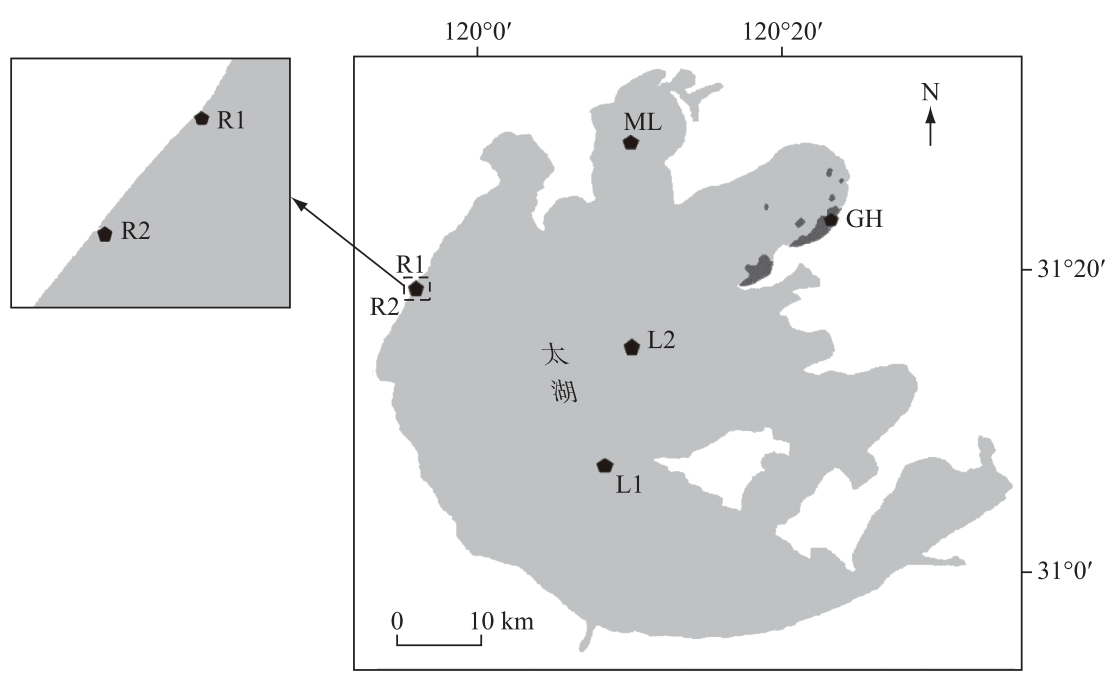

图 1 太湖采样点位置

Fig.1 Location of sampling sites in Lake Taihu

塑料桶中, 低温保存运回实验室.

悬浮颗粒物的收集: 混匀水样, 使用经 $450^{\circ} \mathrm{C}$ 灼烧并紫外灭菌过的 Whatman $(\mathrm{GF} / \mathrm{F}, \varnothing 47 \mathrm{~mm})$ 滤膜过 滤 ${ }^{[10-11]}$, 待滤膜完全堵住后, 记录过滤的水样体积. 将收集悬浮颗粒物的滤膜剪碎, 置于 $2 \mathrm{ml}$ 灭菌离心管中, $-20^{\circ} \mathrm{C}$ 保存, 3 天内完成样品 DNA 的提取.

\section{2 样品分析}

2.2.1 理化性质分析 采用便携式测定仪 (HACH HQ30D) 对水体 $\mathrm{pH} 、 \mathrm{DO} 、$ Temp、Eh 进行现场测定. 使用塞式 透明度盘测定水体透明度. 总氮 (TN)、总磷 (TP)、溶解性总氮 (DTN)、溶解性总磷 (DTP) 浓度等水质指标的 测定参照《湖泊富营养化调查规范》(第二版) ${ }^{[41]}$, 颗粒态氮 (磷) 浓度为 TN ( TP ) 与 DTN (DTP) 浓度的差值. 叶绿素 a (Chl.a) 浓度采用丙酮提取法测定 ${ }^{[42]}$. 水体碱性磷酸酶活性 (APA) 采用对硝基苯磷酸二钠 (p-NPP) 法测定 ${ }^{[43]}$, APA 以每小时每升水样产生对硝基苯酚 (PNP) 的 nmol 数表示. 总有机碳 (TOC) 浓度依据《水质 总有机碳的测定燃烧氧化一非分散红外吸收法》(HJ 501-2009), 采用总有机碳分析仪 (multi N/C 3100) 进 行测定.

2.2.2 悬浮颗粒物细菌总 DNA 提取 使用 FastDNA ${ }^{\mathrm{TM}}$ SPIN Kit (Mo-Bio Laboratories, Carlsbad, CA, USA) 试 剂盒提取悬浮颗粒物细菌总 DNA, 具体操作方法参照说明书进行. 提取后的 DNA 于 $-20^{\circ} \mathrm{C}$ 保存, 用于后续分 子生物学分析.

2.2.3 phoX、phoD 基因荧光定量 PCR 分析 使用 StepOne plus 苂光定量 PCR 仪 (Applied Biosystems) 对碱性 磷酸酶编码基因 $p h o X$ 、 $p h o D$ 进行 $\mathrm{qPCR}$ 定量分析.

扩增体系为: $10 \mu \mathrm{l} \mathrm{SYBR}{ }^{\odot}$ Premix Ex Taq ${ }^{\mathrm{TM}}$ (TaKaRa Biotech, Dalian, China) , $0.4 \mu \mathrm{l}$ 上引物, $0.4 \mu \mathrm{l}$ 下引 物, $2 \mu \mathrm{l} \mathrm{DNA}(10 \sim 20 \mathrm{ng})$, 加灭菌去离子水至 $20 \mu \mathrm{l}$. 碱性磷酸酶编码基因 $p h o X^{[21]}$ 和 $p h o D^{[31]}$ 引物序列与反 应程序参照文献. 所有样品均进行 3 个重复, 取 3 次重复的均值作为功能基因拷贝数.

\section{3 数据处理与分析}

采用 Origin 9.0 对水体环境因子浓度和 $p h o X 、 p h o D$ 基因丰度的分布作图. SPSS 19.0 对水环境因子、细菌 碱性磷酸酶基因丰度进行单因素方差分析 (One-way ANOVA) 和 T 检验 (paired T-test); 对 $p h o X$ 和 $p h o D$ 基因 丰度与环境因子相关性分析采用 Pearson 相关性分析. 


\section{3 结果与讨论}

\section{1 各生态类型湖区水体物理参数}

各生态类型湖区水体物理参数如表 1 所示. 9 月, 蓝藻和水生植物生长旺盛, 光合作用增加, 藻型区、草 型区、湖心区水体 DO 浓度显著高于 6 月. 河口区 DO 浓度在 $6 、 9$ 两月均显著低于其他湖区. 河口区 $\mathrm{pH}$ 与 DO 浓度呈现相似的变化特征, 在 6、9 两月也显著低于其他湖区.

\section{表 1 太湖各采样点物理参数*}

Tab.1 Physical parameters of sampling sites in Lake Taihu

\begin{tabular}{|c|c|c|c|c|c|c|c|}
\hline \multirow{2}{*}{ 指标 } & \multirow{2}{*}{ 月份 } & \multirow{2}{*}{$\begin{array}{c}\text { 藻型湖区 } \\
\text { 梅梁湾 (ML) }\end{array}$} & \multicolumn{2}{|c|}{ 河口区 } & \multicolumn{2}{|c|}{ 湖心区 } & \multirow{2}{*}{$\begin{array}{c}\text { 草型湖区 } \\
\text { 贡湖湾 ( GH) }\end{array}$} \\
\hline & & & 洪巷港 ( R1) & 陈东港 ( R2) & 湖心 ( L1) & 湖心 ( L2) & \\
\hline \multirow[t]{2}{*}{$\mathrm{T} /{ }^{\circ} \mathrm{C}$} & 6 & $24.9 \pm 0.1 \mathrm{c} / \mathrm{B}$ & $25.4 \pm 0.1 \mathrm{~b} / \mathrm{B}$ & $25.4 \pm 0.0 \mathrm{~b} / \mathrm{B}$ & $25.0 \pm 0.1 \mathrm{c} / \mathrm{A}$ & $24.8 \pm 0.1 \mathrm{c} / \mathrm{A}$ & $26.1 \pm 0.0 \mathrm{a} / \mathrm{A}$ \\
\hline & 9 & $26.2 \pm 0.2 \mathrm{c} / \mathrm{A}$ & $27.6 \pm 0.1 \mathrm{ab} / \mathrm{A}$ & $27.3 \pm 0.1 \mathrm{ab} / \mathrm{A}$ & $28.5 \pm 0.7 \mathrm{a} / \mathrm{A}$ & $28.2 \pm 1.0 \mathrm{a} / \mathrm{A}$ & $27.6 \pm 0.5 \mathrm{ab} / \mathrm{A}$ \\
\hline \multirow[t]{2}{*}{$\mathrm{pH}$} & 6 & $9.22 \pm 0.02 \mathrm{a} / \mathrm{A}$ & $7.47 \pm 0.01 \mathrm{~d} / \mathrm{A}$ & $7.48 \pm 0.00 \mathrm{~d} / \mathrm{A}$ & $8.45 \pm 0.04 \mathrm{c} / \mathrm{A}$ & $8.59 \pm 0.07 \mathrm{~b} / \mathrm{A}$ & $8.37 \pm 0.06 \mathrm{c} / \mathrm{A}$ \\
\hline & 9 & $8.80 \pm 0.05 \mathrm{a} / \mathrm{B}$ & $7.52 \pm 0.02 \mathrm{c} / \mathrm{A}$ & $7.58 \pm 0.02 \mathrm{c} / \mathrm{A}$ & $8.54 \pm 0.06 \mathrm{ab} / \mathrm{A}$ & $8.24 \pm 0.28 \mathrm{~b} / \mathrm{A}$ & $8.86 \pm 0.28 \mathrm{a} / \mathrm{A}$ \\
\hline $\mathrm{DO} /$ & 6 & $7.81 \pm 0.04 \mathrm{bc} / \mathrm{B}$ & $4.02 \pm 0.01 \mathrm{~d} / \mathrm{A}$ & $4.09 \pm 0.02 \mathrm{~d} / \mathrm{B}$ & $8.08 \pm 0.11 \mathrm{ab} / \mathrm{B}$ & $8.36 \pm 0.06 \mathrm{a} / \mathrm{B}$ & $7.75 \pm 0.28 \mathrm{c} / \mathrm{B}$ \\
\hline$(\mathrm{mg} / \mathrm{L})$ & 9 & $10.18 \pm 0.23 \mathrm{~b} / \mathrm{A}$ & $4.28 \pm 0.04 \mathrm{e} / \mathrm{A}$ & $4.73 \pm 0.03 \mathrm{~d} / \mathrm{A}$ & $10.97 \pm 0.17 \mathrm{a} / \mathrm{A}$ & $9.02 \pm 0.08 \mathrm{c} / \mathrm{A}$ & $10.65 \pm 0.19 \mathrm{a} / \mathrm{A}$ \\
\hline \multirow[t]{2}{*}{$\mathrm{Eh} / \mathrm{mV}$} & 6 & $155.9 \pm 42.0 \mathrm{~b} / \mathrm{A}$ & $226.7 \pm 6.9 \mathrm{a} / \mathrm{A}$ & $197.1 \pm 6.1 \mathrm{ab} / \mathrm{A}$ & $181.8 \pm 6.9 \mathrm{ab} / \mathrm{A}$ & $161.7 \pm 9.2 \mathrm{~b} / \mathrm{A}$ & $154.1 \pm 6.9 \mathrm{~b} / \mathrm{A}$ \\
\hline & 9 & $212.0 \pm 11.3 \mathrm{a} / \mathrm{A}$ & $156.0 \pm 5.7 \mathrm{~b} / \mathrm{B}$ & $141.0 \pm 8.5 \mathrm{~b} / \mathrm{A}$ & - & - & $151.0 \pm 22.6 \mathrm{~b} / \mathrm{A}$ \\
\hline
\end{tabular}

$*$ 不同湖区的采样点间的差异度以小写字母标注在数据后, $P<0.05$; 不同月份的采样点间的差异度以大写字母标注在数 据后, $P<0.05$; 大小写字母用“〉”隔开.

\section{2 各生态类型湖区的水环境指标}

Chl.a 是判断水体富营养化程度的重要指标. 6 月,太湖各湖区 Chl. a 平均浓度为 $20.72 \mu \mathrm{g} / \mathrm{L}$, 河口区和 藻型区两湖区 $\mathrm{Chl} . \mathrm{a}$ 平均浓度为 $29.26 \mu \mathrm{g} / \mathrm{L}$, 显著高于湖心区和草型区 (平均浓度为 $11.71 \mu \mathrm{g} / \mathrm{L}$ ). 9 月,除河 口区外, 其他各湖区 Chl.a 浓度显著增高, 各湖区平均浓度增高至 $116.44 \mu \mathrm{g} / \mathrm{L}$. 藻型区 Chl. a 浓度最高, 达 $438.60 \mu \mathrm{g} / \mathrm{L}$, 显著高于其他湖区, 其次为湖心区 $(77.69 \mu \mathrm{g} / \mathrm{L}$ ), 河口区最低 $(19.32 \mu \mathrm{g} / \mathrm{L}$ ) (图 2a). 吕学研 等 ${ }^{[44]}$ 和朱广伟等 ${ }^{[40]}$ 对太湖 Chl.a 多年的月均浓度调查表明, 湖体 8、9、10 月藻类现存量较高, 最高值均出现 在 9 月。

6 月, 太湖各湖区水体 TP 平均浓度为 $0.14 \mathrm{mg} / \mathrm{L}$. 空间分布上, 河口区 TP 浓度 $(0.23 \mathrm{mg} / \mathrm{L})$ 显著高于藻 型区、草型区和湖心区 (平均浓度为 $0.10 \mathrm{mg} / \mathrm{L}$ ) (图 $2 \mathrm{~b}$ ). 陈东港是太湖 3 条最大的人湖河流之一, 全年均处 于人流状态 ${ }^{[37]}$. 朱金格等 ${ }^{[45]}$ 于 2014 年对 21 条环湖河道进行了逐月流量观测, 指出西北部河道总体为人湖 河道, 年均最大人湖流量出现在陈东港 $\left(84.1 \mathrm{~m}^{3} / \mathrm{s}\right)$, 陈东港是 TN 和 TP 的主要输人河道. 因此可推断, 陈东 港和洪巷港两河口区高浓度的 TP 可能与外源输人有关. 9 月,各湖区水体 $\mathrm{TP}$ 平均浓度升高至 $0.26 \mathrm{mg} / \mathrm{L}$. 与 6 月相比, 藻型区 $(0.64 \mathrm{mg} / \mathrm{L}$ ) 和湖心区 (平均浓度为 $0.21 \mathrm{mg} / \mathrm{L}$ ) TP 浓度在 9 月显著增加, 河口区和草型 区水体 TP 浓度有变化,但不显著. 9 月藻型区水体 TP 浓度显著高于其他湖区. 进一步分析表明,9 月各生态 类型湖区水体 TP 均以颗粒态为主, 占比高达 $90 \%$ 以上,与已有的研究结果 ${ }^{[39,45]}$ 一致. 浅水湖泊颗粒态磷在 湖泊水体中具有重要作用. 张毅敏等 ${ }^{[11]}$ 发现, 太湖水体颗粒态有机磷浓度占颗粒态总磷浓度的 $87.5 \%$ $100 \%$. 日本第 2 大浅水湖泊 Lake Kasumigaura, 颗粒态有机磷的占比为 $63.4 \%$, 远高于沉积物中有机磷的占 比 $(25.3 \%)^{[10]}$. 当湖泊水体溶解态正磷酸盐缺乏时, 在微生物作用下, 颗粒态有机磷的矿化可能是藻类可利 用磷的重要补充. 9 月, 贡湖湾水体 TP 浓度 $(0.07 \mathrm{mg} / \mathrm{L})$ 最低. 9 月沉水植物处于生长旺盛, 吸收了水体部分 可溶解态磷, 导致水体 TP 浓度偏低.

除草型湖区贡湖湾外, 其他湖区 APA 与 TP 浓度的分布趋势大体相同 (图 3a). 6 月, 太湖各湖区水体 $\mathrm{APA}$ 平均值为 $169.02 \mathrm{nmol} /(\mathrm{L} \cdot \mathrm{h})$, 河口区 $\mathrm{APA}(253.70 \mathrm{nmol} /(\mathrm{L} \cdot \mathrm{h}))$ 显著高于其他湖区. 9 月, 太湖各湖区 水体 $\mathrm{APA}$ 平均值升高至 $581.90 \mathrm{nmol} /(\mathrm{L} \cdot \mathrm{h})$. 与 6 月相比, 藻型区、湖心区和草型区的 APA 显著增加, 河口 

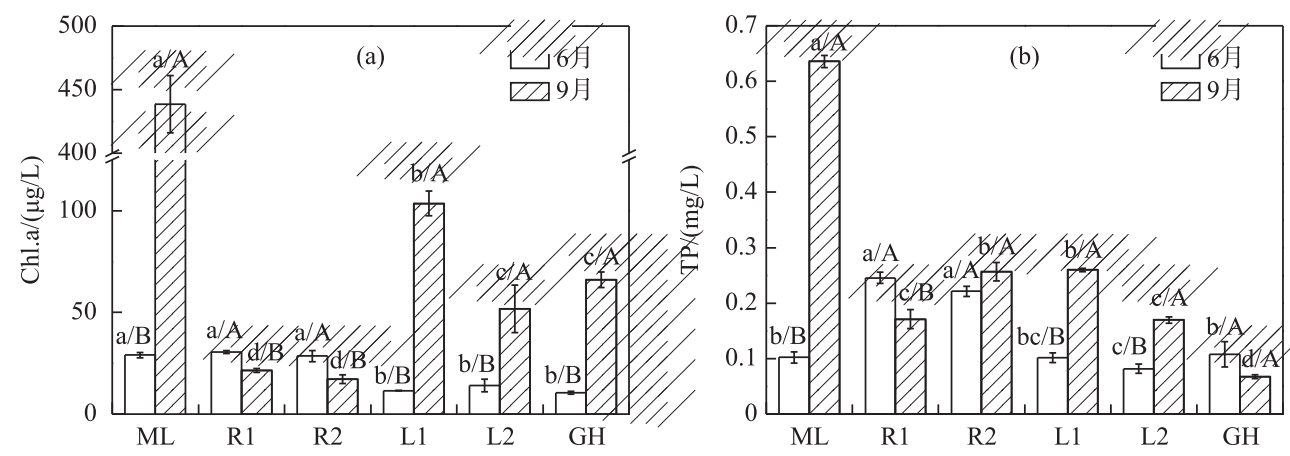

图 2 太湖各湖区水体叶绿素 a (a) 和总磷 $(\mathrm{b})$ 浓度

（误差线基于 3 个重复实验得出, 不同湖区的采样点间的差异度以小写字母标注在误差线上方, $P<0.05$; 不同月份的采样点间的差异度以大写字母标注在误差线上方, $P<0.05$;下同)

Fig.2 Chlorophyll-a (a) and total phosphorus (b) concentrations in different zones of Lake Taihu 区变化无显著差异.

6 月, 太湖各湖区 $\mathrm{TN}$ 平均浓度为 $1.67 \mathrm{mg} / \mathrm{L}$, 河口区 (平均浓度为 $3.35 \mathrm{mg} / \mathrm{L}$ ) 显著高于其他湖区, 湖心 区最低 (平均浓度为 $0.52 \mathrm{mg} / \mathrm{L}$ ), 草、藻湖区 TN 浓度无显著差异 (图 3b). 与 TP 浓度相同, 河口区 TN 的高 浓度应来自外源输人. 9 月,除藻型湖区外, 其他湖区 TN 浓度呈下降趋势, 各湖区 TN 平均浓度降为 0.45 $\mathrm{mg} / \mathrm{L}$, 其中河口区和草型区 TN 浓度显著降低. 9 月, 藻型区 TN 浓度 $(1.15 \mathrm{mg} / \mathrm{L})$ 与 6 月 $(1.09 \mathrm{mg} / \mathrm{L})$ 相比无 显著变化, 但显著高于其他湖区, 湖心区 TN 浓度仍然最低 (平均浓度为 $0.18 \mathrm{mg} / \mathrm{L}$ ). 各生态类型湖区水体 $\mathrm{TN}$ 存在形式不同, 藻型区和草型区以颗粒态氮为主, 平均占 $\mathrm{TN}$ 的 $74.80 \%$; 河口区和湖心区以溶解态氮为 主, 平均占 TN 的 $65.51 \% .2017$ 年 9 月, 朱伟等 ${ }^{[46]}$ 对太湖梅梁湾和贡湖湾水体的监测结果显示, 贡湖湾和梅 梁湾水体 $\mathrm{TN}$ 均以颗粒态氮为主, 约占 $\mathrm{TN}$ 的 $70.83 \%$ 和 $72.22 \%$, 本研究结果与其一致.
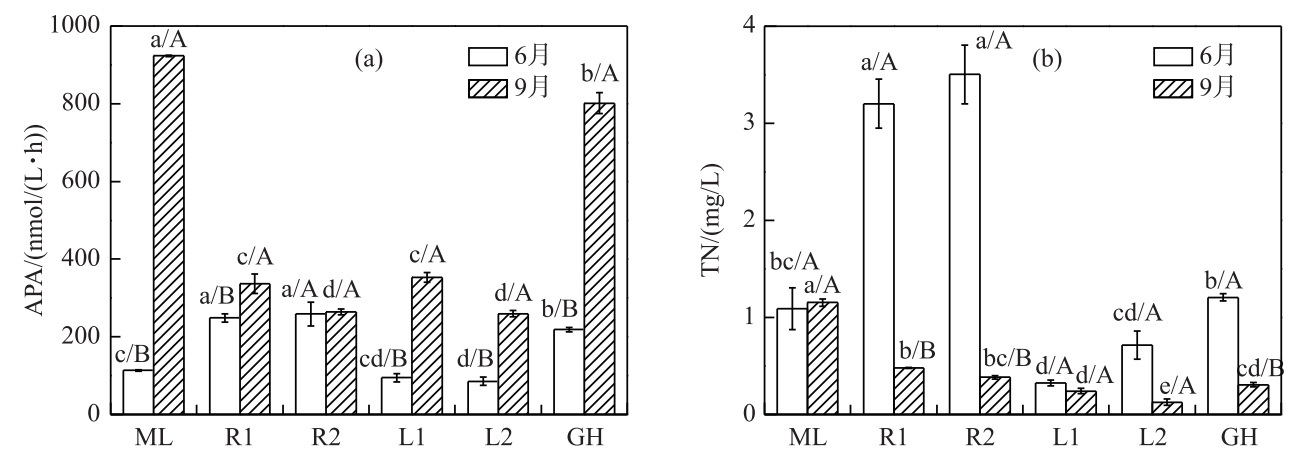

图 3 太湖各湖区水体碱性磷酸酶活性 (a) 和总氮浓度 $(\mathrm{b})$

Fig.3 The alkaline phosphatase activities( a) and total nitrogen concentration(b) in different zones of Lake Taihu

\section{3 各生态类型湖区悬浮颗粒物细菌碱性磷酸酶编码基因 $p h o X$ 的分布特征}

6 月, 太湖各生态类型湖区悬浮颗粒物细菌 $p h o X$ 基因丰度为 $1.61 \times 10^{4} \sim 1.14 \times 10^{5} \mathrm{copies} / \mathrm{L}$, 平均丰度为 $4.85 \times 10^{4}$ copies $/ \mathrm{L} .9$ 月为 $5.33 \times 10^{3} \sim 5.70 \times 10^{4} \mathrm{copies} / \mathrm{L}$, 平均丰度为 $2.51 \times 10^{4} \mathrm{copies} / \mathrm{L}$ (图 $4 \mathrm{a}$ ).

6 月, 太湖悬浮颗粒物细菌 $p h o X$ 基因丰度呈现显著空间异质性 (图 4a), 河口>草型>湖心>藻型, 最大值 出现在河口区 (平均丰度为 $9.18 \times 10^{4} \operatorname{copies} / \mathrm{L}$ ), 最小值出现在藻型区 (平均丰度为 $1.61 \times 10^{4} \mathrm{copies} / \mathrm{L}$ ). 河口 区 $p h o X$ 基因丰度显著高于其他湖区, 与其他湖区 $p h o X$ 基因平均丰度的比值分别为 5.70 (河口/藻型)、3.89 (河口/湖心) 和 2.07 (河口/草型). 前已分析得出, 6 月河口区存在较高的外源输人,外源微生物的引人是河 
口区悬浮颗粒物细菌 $p h o X$ 基因丰度显著高于其他湖区的主要原因. 除河口区外, 草型区悬浮颗粒物细菌 $p h o X$ 基因丰度也显著高于湖心区和藻型区. 草型区长有大量水生植物, 包括沉水植物 (蕰草和苦草) 和浮叶 植物 (菱角). 水生植物是决定浅水湖泊浮游细菌组成的重要因素 ${ }^{[47-48]}$. 水生植物通过产生化感物质和提供 不同的生态位, 从而对浮游细菌产生直接影响; 同时, 水生植物也能通过影响浮游植物和浮游动物的组成, 对浮游细菌产生间接影响 ${ }^{[48]}$. Tang 等 ${ }^{[49]}$ 对太湖细菌群落组成的时空动态研究发现, 尽管浮游细菌和悬浮颗 粒物附着细菌群落组成存在明显的季节性变化, 但两者空间差异小, 细菌群落组成高度重叠. 因此, 水生植 物通过影响悬浮颗粒物附着细菌的组成,进而可以影响悬浮颗粒物附着细菌 $p h o X 、 p h o D$ 基因丰度.

9 月,除草型区外,其他各湖区悬浮颗粒物细菌 $p h o X$ 基因丰度无显著空间分布差异 (图 4a), 最大值出 现在草型区 (平均丰度为 $5.70 \times 10^{4} \mathrm{copies} / \mathrm{L}$ ), 最小值出现在河口区 (平均丰度为 $1.49 \times 10^{4} \mathrm{copies} / \mathrm{L}$ ). 草型区 $p h o X$ 基因丰度显著高于其他各湖区, 平均丰度比值分别为 2.22 (草型/藻型) 、3.82 (草型/河口) 和 3.02 (草 型/湖心). 6 月和 9 月,草型区较高的 $p h o X$ 基因丰度指示, 水生植物对水体悬浮颗粒物细菌 $p h o X$ 基因丰度 具有正面影响.

从时间上看, $6-9$ 月,各生态类型湖区悬浮颗粒物细菌 $p h o X$ 基因丰度随时间呈现不同的变化趋势. 河 口区和湖心区 $p h o X$ 基因丰度呈下降趋势 (图 4a), 平均丰度比值分别为 6.14(6 月/9 月) 和 1.25(6 月/9 月), 其中河口区 9 月 $p h o X$ 基因丰度显著低于 6 月. 结合河口区水体 TN 浓度变化趋势, 可进一步验证, 河口 区悬浮颗粒物 $p h o X$ 基因主要受外源微生物影响. 与 6 月相比, 9 月湖心区 L1 点位的 $p h o X$ 基因丰度呈上升 趋势, 湖心区 L2 点位则呈下降趋势, 但均不显著. 且湖心区 L2 点位悬浮颗粒物 $p h o X$ 基因丰度显著低于 L1 点位. 仔细分析两湖心区水环境指标, 发现除 TP 外, 湖心区 L2 点位水体中, 颗粒态 TN、颗粒态 TOC 和颗粒 态 APA 的比例 ( $16 \%$ 、10\%和 7\%) 远低于湖心区 L1 点位 ( $53 \% 、 35 \%$ 和 30\%). 这表明, L1 和 L2 点位虽同划 归为湖心区, 但由于水环境特征存在差异, 可能存在不同的细菌群落组成, 进而导致悬浮颗粒物 pho $X$ 基因 丰度存在差异, 指示两湖心区需要分开研究. 藻型区和草型区 $p h o X$ 基因丰度均上升, 但都不显著, 丰度比值 分别为 0.63 (6月/9 月) 和 0.78 ( 6 月/9 月), 且草型区 $p h o X$ 基因丰度显著高于藻型区. Dai 等 ${ }^{[33]}$ 对太湖梅梁 湾 (藻型区) 和胥口湾 (草型区) 水体 $p h o X$ 基因丰度的研究得到了相同的结果: 与胥口湾相比, 梅梁湾水体在 夏季 ( 8 月) $p h o X$ 基因丰度较低, 但具有高的碱性磷酸酶活性, 并推测藻型生境和草型生境存在不同的有机 磷矿化模式. 蓝细菌以 $p h o X$ 基因为主 ${ }^{[50]}$. 由图 $2 \mathrm{a}$ 可知, 9 月, 藻型区和草型区水体 Chl. a 浓度均显著高于 6 月, 且藻型区 $\mathrm{Chl} . \mathrm{a}$ 浓度 $(438.60 \mu \mathrm{g} / \mathrm{L})$ 显著高于草型区 $(66.06 \mu \mathrm{g} / \mathrm{L})$. 但在 9 月,藻、草湖区 $p h o X$ 基因丰度 却并未显著增加, 且藻型区 $p h o X$ 基因丰度显著低于草型区. Dai 进一步的研究显示 ${ }^{[33]}$, 不同季节 (春、夏、 秋、冬季), 草、藻型湖区水体 $p h o X$ 基因均以与 $\alpha$-proteobacteria 和 $\beta$-proteobacteria 的 $p h o X$ 基因最相似的基因 型占主导. 且夏季藻型区占比最高 $(38.8 \%)$ 的蓝细菌 pho $X$ 基因与 Synechococcus sp. PCC 最为相似, 而这是一 类广泛分布于海洋中的超微蓝细菌. 微囊藻是太湖水华的优势藻, 占蓝藻总丰度的 $90 \%$ 以上. 太湖微囊藻种 类组成具有时空分布性, $7-11$ 月贡湖湾和梅梁湾均表现为鱼害微囊藻、惠氏微囊藻及铜绿微囊藻顺次成为 优势种的演替过程 ${ }^{[39]}$. 因此我们推测, 本文及文献 $[21,32-34]$ 所使用的 $p h o X$ 基因简并引物对太湖优势微囊 藻蓝细菌不具有保守性,进而可能导致太湖悬浮颗粒物细菌 $p h o X$ 基因丰度被低估.

\section{4 各生态类型湖区悬浮颗粒物细菌碱性磷酸酶编码基因 $p h o D$ 的分布特征}

6 月和 9 月, 太湖各生态类型湖区悬浮颗粒物细菌 $p h o D$ 基因丰度分别为 $4.00 \times 10^{5} \sim 1.98 \times 10^{6} \mathrm{copies} / \mathrm{L}$ 和 $1.20 \times 10^{5} \sim 3.95 \times 10^{5}$ copies $/ \mathrm{L}$, 平均丰度分别为 $1.05 \times 10^{6} \operatorname{copies} / \mathrm{L}$ 和 $3.11 \times 10^{5} \operatorname{copies} / \mathrm{L}$ (图 $4 \mathrm{~b}$ ). 太湖悬浮 颗粒物细菌 $p h o D$ 基因丰度是 $p h o X$ 基因的 $6 \sim 42$ 倍.

6 月,太湖悬浮颗粒物细菌 $p h o D$ 基因丰度呈现显著空间分布差异性（图 4b), 其分布与 $p h o X$ 基因丰度 具有相同特征, 即河口>草型>湖心>藻型区, 最大值出现在河口区 (平均丰度为 $1.88 \times 10^{6} \mathrm{copies} / \mathrm{L}$ ), 最小值 出现在藻型区 (平均丰度为 $4.00 \times 10^{5} \mathrm{copies} / \mathrm{L}$ ). 河口区 $p h o D$ 基因丰度显著高于其他湖区, 平均丰度的比值 分别为 4.71 (河口/藻型) 、3.91 (河口/湖心) 和 1.63 (河口/草型). 和 $p h o X$ 基因一样, 河口区悬浮颗粒物细菌 $p h o D$ 基因的高丰度来源于外源微生物的输人.

9 月, 太湖悬浮颗粒物细菌 $p h o D$ 基因丰度分布亦呈现空间异质性 (图 4b), 湖心 ( L1 点位) > 河口 > 草 型>藻型区>湖心 ( $\mathrm{L} 2$ 点位). 与 $p h o X$ 基因一样, 湖心区 $\mathrm{L} 1$ 与 $\mathrm{L} 2$ 点位的悬浮颗粒物细菌 $p h o D$ 基因丰度呈现 
显著差异,原因分析同 3.3 节.

时间上,悬浮颗粒物细菌 $p h o D$ 基因丰度显示出与 $p h o X$ 基因不同的时间变化特征. 与 6 月相比, 9 月太 湖各生态湖区悬浮颗粒物细菌 $p h o D$ 基因丰度均显著降低. 各湖区 6 月与 9 月 $p h o D$ 基因丰度的比值分别为 1.92 (藻型)、4.90(河口)、 1.74 (湖心) 和 3.48 (草型). 与 $p h o X$ 基因相同的是,外源微生物输人的减少导致河 口细菌 $p h o D$ 基因丰度的显著降低. 与 $p h o X$ 基因不同的是, 蓝藻和水生植物的旺盛生长却显著降低了悬浮 颗粒物细菌 $p h o D$ 基因丰度, 说明这两类基因可能受不同的环境因子制约.
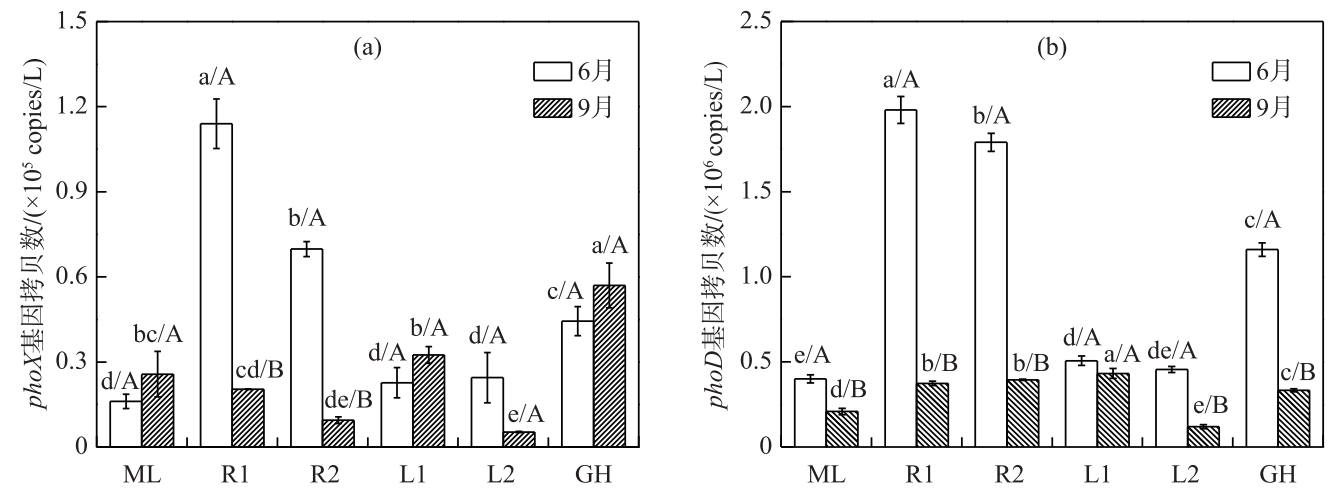

图 4 太湖悬浮颗粒物细菌 $p h o X(\mathrm{a})$ 和 $p h o D(\mathrm{~b})$ 基因丰度分布

Fig.4 Abundance of $\operatorname{phoX}(\mathrm{a})$ and $\operatorname{phoD}(\mathrm{b})$ gene in suspended particles of Lake Taihu

\section{5 碱性磷酸酶编码基因丰度与环境因子的关系}

对 $p h o X$ 和 $p h o D$ 两种碱性磷酸酶编码基因丰度与水体环境因子进行相关性分析, 结果如表 2 和表 3 所 示. 环境因子对悬浮颗粒物细菌 $p h o X$ 和 $p h o D$ 基因丰度的影响复杂.

6 月, 水体 DO 浓度与 $p h o X 、 p h o D$ 基因丰度均呈显著负相关 $(P<0.01) .9$ 月, DO 浓度与 $p h o X$ 基因丰度 呈显著正相关、与 $p h o D$ 基因丰度呈负相关. 9 月蓝藻现存量最高且为水生植物生长旺盛期. 蓝藻和水生植物 的光合作用释氧使得藻、草两湖区水体具有较高的 DO 浓度, 分别为 $10.18 \mathrm{mg} / \mathrm{L}$ 和 $10.65 \mathrm{mg} / \mathrm{L}$ (表 1$)$. 相关 性结果表明, $\mathrm{DO}$ 浓度的升高降低了 $p h o D$ 基因丰度, 但显著增加了 $p h o X$ 基因丰度 $(P<0.01)$. 可以推测, 水体 $\mathrm{DO}$ 浓度的升高改变了含 $p h o X 、 p h o D$ 编码基因的细菌群落组成, 有利于某些含 $p h o X$ 基因细菌的生长, 不利 于某些含 $p h o D$ 基因细菌的生长, 从而导致 $p h o D$ 基因丰度在 9 月显著降低.

6 月, 水体 $\mathrm{APA}$ 与 $p h o X, p h o D$ 基因丰度均呈显著正相关 $(P<0.01) .9$ 月, 水体 $\mathrm{APA}$ 与 $p h o X$ 基因丰度呈 显著正相关 $(P<0.01)$, 而与 $p h o D$ 基因丰度呈负相关性. 除河口区外, 其他各湖区水体 9 月的 APA 均显著高 于 6 月 (图 3a). 9 月, 水体 APA 与 Chl.a 浓度呈显著正相关 $(P<0.01)$, 表明微囊藻是水体 APA 的主要贡献 者. 与 6 月相比, 9 月悬浮颗粒物细菌 $p h o D$ 基因丰度显著降低, $p h o X$ 基因丰度增加不显著, 对应的却是 APA 显著升高. 由于 $p h o X$ 基因简并引物对太湖优势微囊藻蓝细菌不具有保守性, 进而可能导致湖泊, 尤其是藻 型湖区 $p h o X$ 基因丰度被低估. 因此, 在水华暴发期, 与碱性磷酸酶 $\mathrm{phoD}$ 相比较, 碱性磷酸酶 $\mathrm{phoX}$ 在浅水湖 泊生态系统磷循环中可能发挥更为重要的作用. 藻型生境和草型生境存在不同的有机磷矿化模式.

Ragot 等 ${ }^{[25]}$ 对土壤中含 $p h o D$ 基因细菌的研究发现, TN 是土壤中含 $p h o D$ 基因细菌群落的主要影响因 子. 本研究中, 6 月,水体 $\mathrm{TN}$ 浓度与 $p h o X, p h o D$ 基因丰度均呈显著正相关 $(P<0.01)$; 9 月,水体 $\mathrm{TN}$ 浓度与 $p h o X$ 基因丰度呈正相关, 与 $p h o D$ 基因丰度呈负相关,但都不显著. 河口区外源输人的不确定性使得 $\mathrm{TN}$ 浓 度对 $p h o X 、 p h o D$ 基因丰度的影响存在不确定性.

6 月, TP 浓度与 $p h o X 、 p h o D$ 基因丰度均呈显著正相关 $(P<0.01) .9$ 月, TP 浓度与 $p h o X 、 p h o D$ 基因丰度 均呈负相关. Tan 等 ${ }^{[29]}$ 对土壤的研究发现含 $p h o D$ 基因的酸杆菌门丰度随着磷肥的施加而降低, Ragot 等 ${ }^{[25]}$ 对土壤的研究中,也发现含 $p h o D$ 基因的酸杆菌门丰度与树脂可提取磷呈负相关. TP 浓度对 $p h o X 、 p h o D$ 基 因的影响仍需进一步研究. 
表 26 月 $p h o X$ 和 $p h o D$ 基因丰度与水环境因子的相关性

Tab.2 Pearson's correlation coefficient of $p h o X$ and $p h o D$ gene abundances and environmental factors in June

\begin{tabular}{|c|c|c|c|c|c|c|c|c|c|c|}
\hline & phoD & phoX & $\mathrm{TN}$ & $\mathrm{TP}$ & TOC & Chl.a & $\mathrm{pH}$ & $\mathrm{T}$ & APA & DO \\
\hline phoD & 1 & $0.939^{\text {*** }}$ & $0.923^{\text {*** }}$ & $0.927^{\text {*** }}$ & -0.013 & $0.512 *$ & $-0.925^{* * *}$ & $0.586^{*}$ & $0.939^{* *}$ & $-0.935^{* * *}$ \\
\hline phoX & & 1 & $0.849^{\text {*** }}$ & 0.920 ** & 0.160 & $0.544^{*}$ & $-0.879^{* *}$ & 0.435 & $0.822^{* *}$ & $-0.896^{* *}$ \\
\hline $\mathrm{TN}$ & & & 1 & $0.940^{\text {*** }}$ & 0.255 & 0.730 ** & $-0.831^{* *}$ & 0.356 & $0.855^{* *}$ & $-0.970^{* *}$ \\
\hline $\mathrm{TP}$ & & & & 1 & 0.262 & $0.721^{\text {*** }}$ & $-0.860^{* * *}$ & 0.330 & $0.828^{* *}$ & -0.980 ** \\
\hline TOC & & & & & 1 & $0.648^{* * *}$ & -0.042 & $-0.769^{* *}$ & -0.214 & -0.283 \\
\hline Chl.a & & & & & & 1 & -0.334 & -0.118 & 0.448 & $-0.729^{* *}$ \\
\hline $\mathrm{pH}$ & & & & & & & 1 & -0.415 & $-0.802^{* *}$ & $0.880^{* * *}$ \\
\hline $\mathrm{T}$ & & & & & & & & 1 & $0.747^{* *}$ & -0.309 \\
\hline $\mathrm{APA}$ & & & & & & & & & 1 & $-0.838^{* *}$ \\
\hline DO & & & & & & & & & & 1 \\
\hline
\end{tabular}

* 表示 $P<0.05, * *$ 表示 $P<0.01$.

表 39 月 $p h o X$ 和 $p h o D$ 基因丰度与水环境因子的相关性

Tab.3 Pearson's correlation coefficient of $p h o X$ and $p h o D$ gene abundances and environmental factors in September

\begin{tabular}{|c|c|c|c|c|c|c|c|c|c|c|}
\hline & phoD & phoX & $\mathrm{TN}$ & $\mathrm{TP}$ & TOC & Chl.a & $\mathrm{pH}$ & $\mathrm{T}$ & APA & DO \\
\hline phoD & 1 & 0.322 & -0.210 & -0.288 & -0.306 & -0.383 & -0.295 & 0.244 & -0.216 & -0.269 \\
\hline phoX & & 1 & 0.031 & -0.215 & 0.346 & 0.119 & $0.657^{\text {*** }}$ & 0.052 & $0.648^{* * *}$ & $0.556^{*}$ \\
\hline $\mathrm{TN}$ & & & 1 & $0.876^{* *}$ & $0.880^{* *}$ & $0.888^{* *}$ & 0.242 & $-0.943^{* *}$ & $0.696^{* *}$ & 0.040 \\
\hline $\mathrm{TP}$ & & & & 1 & $0.797^{\text {*** }}$ & $0.912^{* *}$ & 0.260 & $-0.761^{\text {*** }}$ & $0.464^{* *}$ & 0.170 \\
\hline TOC & & & & & 1 & $0.962^{* *}$ & $0.673^{* *}$ & $-0.759^{\text {*** }}$ & $0.898^{* *}$ & $0.496^{*}$ \\
\hline Chl.a & & & & & & 1 & $0.580^{*}$ & $-0.746^{* *}$ & $0.749^{* *}$ & 0.450 \\
\hline $\mathrm{pH}$ & & & & & & & 1 & -0.072 & $0.747^{* * *}$ & $0.958^{* *}$ \\
\hline $\mathrm{T}$ & & & & & & & & 1 & $-0.637^{* *}$ & 0.167 \\
\hline APA & & & & & & & & & 1 & $0.530^{*}$ \\
\hline DO & & & & & & & & & & 1 \\
\hline
\end{tabular}

*表示 $P<0.05, * *$ 表示 $P<0.01$.

\section{4 结论}

1) 太湖不同生态类型湖区, 悬浮颗粒物细菌 $p h o D$ 基因丰度是 $p h o X$ 基因丰度的 $6 \sim 42$ 倍. 6 月 $p h o X$ 基 因平均丰度为 $4.85 \times 10^{4}$ copies $/ \mathrm{L}, p h o D$ 基因平均丰度为 $1.05 \times 10^{6}$ copies $/ \mathrm{L} .9$ 月 $p h o X$ 基因平均丰度为 $2.51 \times$ $10^{4}$ copies $/ \mathrm{L}, p h o D$ 基因平均丰度为 $3.11 \times 10^{5} \operatorname{copies} / \mathrm{L}$. 悬浮颗粒物细菌 $p h o X$ 基因丰度可能被低估.

2 ) 太湖悬浮颗粒物细菌 $p h o X$ 和 $p h o D$ 基因丰度呈现显著的时空异质性. 河口区 $p h o X 、 p h o D$ 基因丰度受 外源微生物引人的控制; 草型湖区 $p h o X$ 和 $p h o D$ 基因丰度显著高于藻型湖区, 指示水生植物对悬浮颗粒物 细菌 $p h o X$ 和 $p h o D$ 基因丰度具有重要贡献. 水华暴发期, 碱性磷酸酶 PhoX 在浅水湖泊生态系统磷循环中可 能发挥重要作用.

3 ) 水体 DO 、 TN 和 TP 浓度对悬浮颗粒物细菌 $p h o X$ 和 $p h o D$ 基因丰度具有显著影响. DO 浓度的增加有 利于含 $p h o X$ 基因细菌的生长. $\mathrm{TN}$ 和 $\mathrm{TP}$ 浓度对 $p h o X 、 p h o D$ 基因丰度的影响需更深人的研究.

\section{5 参考文献}

[ 1 ] Hecky RE, Kilham P. Nutrient limitation of phytoplankton in freshwater and marine environments: A review of recent evidence on the effects of enrichment1. Limnology \& Oceanography, 1988, 33(4part2): 796-822.

[ 2 ] Schindler DW, Carpenter SR, Chapra SC et al. Reducing phosphorus to curb lake eutrophication is a success. Environmen- 
tal Science \& Technology, 2016, 50(17) : 8923-8929. DOI: 10.1021/acs.est.6b02204.

[ 3 ] Jeppesen E, Søndergaard M, Jensen JP et al. Lake responses to reduced nutrient loading-an analysis of contemporary longterm data from 35 case studies. Freshwater Biology, 2005, 50 (10) : 1747-1771. DOI: 10.1111/j. 1365-2427.2005.0 1415.x.

[ 4 ] Søndergaard M, Jensen JP, Jeppesen E. Role of sediment and internal loading of phosphorus in shallow lakes. Hydrobiologia, 2003, 506-509(1/2/3): 135-145.

[ 5 ] Turner A, Millward GE. Suspended particles: Their role in estuarine biogeochemical cycles. Estuarine Coastal \& Shelf Science, 2002, 55(6) : 857-883. DOI: 10.1006/ecss.2002.1033.

[ 6 ] Zhang L, Qin Y, Han C et al. Spatial-temporal variations of phosphorus fractions in surface water and suspended particles in the Daliao River Estuary, Northeast China. Environmental Science \& Pollution Research, 2016, 23(16) : 1-8. DOI: 10. 1007/s11356-016-6517-4.

[ 7 ] Yu YJ, Fang XJ, Wang SR et al. Spatial and temporal distribution patterns of loadings of different phosphorous forms in Lake Dianchi. J Lake Sci, 2017, 29(1) : 59-68. DOI: 10.18307/2017.0107. [余佑金, 方向京, 王圣瑞等. 滇池水体 不同形态磷负荷时空分布特征. 湖泊科学, 2017, 29(1) : 59-68.]

[ 8 ] Hong YP, Ye M, Zang XP. Study on the influence of nitrogen and phosphorus in water in the Three Gorges Reservoir. China Water Resource, 2004, (20) : 23-24. [ 洪一平, 叶闽, 藏小平. 三峡水库水体中氮磷影响研究. 中国水利, 2004, (20): 23-24.]

[ 9 ] Wang M, Wu XF, Li DP et al. Annual variation of different phosphorus forms and response of algae growth in Meiliang bay of Taihu Lake. Environmental Science, 2015, 36(1) : 80-86. DOI: 10.1007/s11356-016-6517-4. [汪明, 武晓飞, 李大 鹏等. 太湖梅梁湾不同形态磷周年变化规律及藻类响应研究. 环境科学, 2015, 36(1): 80-86. ]

[10] Shinohara R, Imai A, Kawasaki N et al. Biogenic phosphorus compounds in sediment and suspended particles in a shallow eutrophic lake: a ${ }^{31} \mathrm{P}$-nuclear magnetic resonance $\left({ }^{31} \mathrm{P}\right.$ NMR $)$ study. Environmental Science \& Technology, 2012, 46 (19) : 10572-10578. DOI: 10.1021/es301887z.

[11] Zhang YM, Wang Y, Yang F et al. The spatial distribution and degradation characteristic of phosphorus in suspended particulate matter among different ecological types in Taihu. China Environmental Science, 2016, 36(7) : 2128-2138. [张毅 敏, 王宇, 杨飞等. 太湖不同生态型湖区悬浮颗粒磷空间分布和降解速率. 中国环境科学, 2016, 36(7): 2128-2138. ]

[12] Yoshimura T, Nishioka J, Saito H et al. Distributions of particulate and dissolved organic and inorganic phosphorus in North Pacific surface waters. Mar Chem, 2007, 103(1) : 112-121. DOI: 10.1016/j.marchem.2006.06.011.

[13] Kobori H, Taga N. Phosphatase activity and its role in the mineralization of organic phosphorus in coastal sea water. Journal of Experimental Marine Biology \& Ecology, 1979, 36(1) : 23-39. DOI: 10.1016/0022-0981(79) 90098-4.

[14] Chróst RJ, Overbeck J. Kinetics of alkaline phosphatase activity and phosphorus availability for phytoplankton and bacterioplankton in lake plusee (North German Eutrophic Lake). Microbial Ecology, 1987, 13 (3) : 229-248. DOI: 10. 1007/BF02025000.

[15] Sharpley AN. Phosphorus cycling in unfertilized and fertilized agricultural soils1. Soil Science Society of America Journal, 1985, 49(4) : 905-911.

[16] Tarafdar JC, Jungk A. Phosphatase activity in the rhizosphere and its relation to the depletion of soil organic phosphorus. Biology \& Fertility of Soils, 1987, 3(4) : 199-204.

[17] Som AB, Samanta S, Manna SK. Water alkaline phosphatase activity and phosphorus availability during summer in inland water bodies. Indian Journal of Fisheries, 2011, 55(2) : 167-173.

[18] Zhao G, Du J, Jia Y et al. The importance of bacteria in promoting algal growth in eutrophic lakes with limited available phosphorus. Ecological Engineering, 2012, 42(9) : 107-111. DOI: 10.1016/j.ecoleng.2012.02.007.

[ 19] Huang RZ, Wang SR, Zhao HC et al. Study on temporal and spatial variation of alkaline phosphatase activity in the surface sediments of Erhai Lake. Research of Environmental Sciences, 2013, 26(3): 250-255. [黄睿智, 王圣瑞, 赵海超等. 洱 海表层沉积物碱性磷酸酶活性时空变化. 环境科学研究, 2013, 26(3) : 250-255.]

[20] Zhang P, Feng J, Li Z et al. Alkaline phosphatase activity and its kinetics in Lake Gaoyang, Pengxi River during high water level of the Three Gorges Reservoir. J Lake Sci, 2015, 27 (4) : 629-636. DOI: 10.18307/2015.0410. [张萍, 冯婧, 李哲等. 三峡澎溪河高阳平湖高水位时碱性磷酸酶活性及其动力学特征. 湖泊科学, 2015, 27(4): 629-636.] 
[21] Sebastian M, Ammerman JW. The alkaline phosphatase PhoX is more widely distributed in marine bacteria than the classicalPhoA. Isme Journal, 2009, 3(5) : 563-572. DOI: 10.1038/ismej.2009.10.

[22] Luo H, Zhang H, Long RA et al. Depth distributions of alkaline phosphatase and phosphonate utilization genes in the North Pacific Subtropical Gyre. Aquatic Microbial Ecology, 2011, 62(1) : 61-69. DOI: 10.3354/ame01458.

[23] Zhao DD, Luo JF, Huang XY et al. Diversity of bacterial APASE phoD gene in the Pearl River water. Acta Scientiae Circumstantiae, 2015, 35(3) : 722-728. DOI: 10.13671/j.hjkxxb.2014.0876. [ 赵丹丹, 罗剑飞, 黄晓燕等. 珠江水体中 细菌碱性磷酸酶基因 $p h o D$ 的多样性. 环境科学学报, 2015, 35(3) : 722-728.]

[24] Luo H, Benner R, Long RA et al. Subcellular localization of marine bacterial alkaline phosphatase. Proceedings of the National Academy of Sciences of the United States of America, 2009, 106 ( 50): 21219-21223. DOI: 10. 1073/ pnas.0907586106.

[25] Ragot SA, Kertesz MA, Mésź́ros É et al. Soil $p h o D$ and $p h o X$ alkaline phosphatase gene diversity responds to multiple environmental factors. Fems Microbiology Ecology, 2017, 93(1) : 118-120

[26] Ragot SA, Kertesz MA, Bunemann EK. phoD alkaline phosphatase gene diversity in soil. Applied \& Environmental Microbiology, 2015, 81(20) : 7281-7289. DOI: 10.1128 /AEM.01823-15.

[27] Chen $\mathrm{X}$, Jiang $\mathrm{N}$, Chen $\mathrm{Z}$ et al. Response of soil phoD phosphatase gene to long-term combined applications of chemical fertilizers and organic materials. Applied Soil Ecology, 2017, 119: 197-204. DOI: 10.1016/j.apsoil.2017.06.019.

[28] Luo G, Ling N, Nannipieri P et al. Long-term fertilisation regimes affect the composition of the alkaline phosphomonoesterase encoding microbial community of a vertisol and its derivative soil fractions. Biology Fertility of Soils, 2017, 53(4) : 375-388. DOI: $10.1007 / \mathrm{s} 00374-017-1183-3$.

[29] Tan H, Barret M, Mooij MJ et al. Long-term phosphorus fertilisation increased the diversity of the total bacterial community and the phoD phosphorus mineraliser group in pasture soils. Biology Fertility of Soils, 2013, 49(6) : 661-672. DOI: 10. 1007/s00374-012-0755-5.

[30] Lagos LM, Acuña JJ, Maruyama F et al. Effect of phosphorus addition on total and alkaline phosphomonoesterase-harboring bacterial populations in ryegrass rhizosphere microsites. Biology Fertility of Soils, 2016, 52(7) : 1007-1019. DOI: 10. 1007/s00374-016-1137-1.

[31] Sakurai M, Wasaki J, Tomizawa Y et al. Analysis of bacterial communities on alkaline phosphatase genes in soil supplied with organic matter. Soil Science and Plant Nutrition, 2008, 54(1) : 62-71. DOI: 10.1111/j.1747-0765.2007.00210.x.

[32] Dai JY, Chen D, Gao G et al. Recovery of novel alkaline phosphatase-encoding genes ( $p h o X)$ from eutrophic Lake Taihu. Canadian Journal of Microbiolog, 2014, 60(3) : 167-171. DOI: 10.1139/cjm-2013-0755.

[33] Dai JY, Chen D, Wu SQ et al. Comparative analysis of alkaline phosphatase-encoding genes (phoX) in two contrasting zones of Lake Taihu. Canadian Journal of Microbiolog, 2015, 61(3) : 227-236. DOI: 10.1139/cjm-2014-0446.

[34] Dai JY, Gao G, Wu SQ et al. Comparing alkaline phosphatase phox-encoding genes in two contrasting habitats of the large eutrophic Lake Taihu, China. Geomicrobiology, 2018, 35(6) : 528-536. DOI:10.1080/01490451.2017.1420709.

[35] Gao G, Zhu GW, Qin BQ et al. Alkaline phosphatase activity and the phosphorus mineralization rate of Lake Taihu. Science in China: Series D: Earth Sciences, 2006, 49(s1) : 176-185. DOI:10.1007/s11430-006-8117-5.

[36] Yuan HZ, Shen J, Liu EF et al. Space distribution characteristics and diversity analysis of phosphorus from overlying water and surface sediments in Taihu Lake. Environmental Science, 2010, 31 (4) : 954-960. DOI: 10.13227/j. hjkx.2010.04. 004. [袁和忠, 沈吉, 刘恩峰等. 太湖水体及表层沉积物磷空间分布特征及差异性分析. 环境科学, 2010, 31(4) : 954-960.]

[37] Qin BQ, Xu PZ, Wu QL et al. Environmental issues of Lake Taihu, China. Hydrobiologia, 2007, 581( 1) : 3-14. DOI: 10.1007/s10750-006-0521-5.

[38 ] Li JY, Wu XX, Xu HS et al. Research on current status and management of aquatic plants in Taihu Lake. Environmental Science \& Management, 2014, 39(3) : 118-120. [李继影, 吴昕贤, 徐恒省等. 太湖大型水生植物的现状与管理研 究. 环境科学与管理, 2014, 39(3): 118-120.]

[39] Sun QQ, Zhu W, Li M. Spatial and temporal variations of Microcystis colonies and their influencing factors in Gonghu Bay and Meiliang Bay of Lake Taihu. J Lake Sci, 2015, 27(5): 865-872. DOI: 10.18307/2015.0512. [孙千千, 朱伟, 李 明. 太湖贡湖湾和梅梁湾微囊藻群落的时空分布及驱动因子. 湖泊科学, 2015, 27(5): 865-872.]

[40] Zhu GW, Qin BQ, Zhang YL et al. Variation and driving factors of nutrients and chlorophyll- $a$ concentrations in northern 
region of Lake Taihu, China, 2005-2017. J Lake Sci, 2018, 30(2) : 279-295. DOI: 10.18307/2018.0201. [朱广伟, 秦 伯强, 张运林等. 2005-2017 年北部太湖水体叶绿素 a 和营养盐变化及影响因素. 湖泊科学, 2018, 30(2): 279-295.]

[41] Jin XC, Tu QY eds. The standard methods in lake eutrophication investigation: second edition. Beijing: China Environmental Science Press, 1990. [ 金相灿, 屠清瑛. 湖泊富营养化调查规范: 第 2 版. 北京: 中国环境科学出版 社, 1990.]

[42] Editorial board of "Water and wastewater monitoring and analysis method”, Ministry of Environmental Protection of the People's Republic of China ed. Monitoring and analysis methods of water and wastewater: fourth edition. Beijing: China Environmental Science Press, 2002. [国家环境保护总局《水和废水监测分析方法》编委会. 水和废水监测分析方 法: 第 4 版. 北京: 中国环境科学出版社, 2002.]

[43] Riadas O, Pinkas R. Arylsulfatase and alkaline phosphatase (APASE) activity in sediments of Lake Kinneret, Israel. Water Air \& Soil Pollution, 1997, 99(1/2/3/4) : 671-679.

[44] Lv XY, Wu SQ, Zhang Y et al. Analysis on variation of main indicators of eutrophication and mutrition level in Taihu lake. Journal of Water Resources Water Engineering, 2014, 25(4): 1-6. [吕学研, 吴时强, 张咏等. 太湖富营养化主要指标 及营养水平变化分析. 水资源与水工程学报, 2014, 25(4): 1-6.]

[45] Zhu JG, Liu X, Deng J et al. Pollutant transport rates in the rivers around western Lake Taihu. J Lake Sci, 2018, 30(6) : 1509-1517. DOI: 10.18307/2018.0603. [朱金格, 刘金金, 邓建才等. 太湖西部环湖河道污染物输移速率变化特征. 湖泊科学, 2018, 30(6): 1509-1517.]

[46] Zhu W, Tan YQ, Wang RC et al. The trend of water quality variation and analysis in typical area of Lake Taihu, 20102017. J Lake Sci , 2018, 30(2) : 296-305. DOI: 10.18307/2018.0202. [ 朱伟, 谈永琴, 王若辰等. 太湖典型区 20102017 年间水质变化趋势及异常分析. 湖泊科学, 2018, 30(2): 296-305.]

[47] Wu QL, Zwart G, Wu JF et al. Submersed macrophytes play a key role in structuring bacterioplankton community composition in the large, shallow, subtropical Taihu Lake, China. Environmental Microbiology, 2007, 9(11) : 2765-2774. DOI: 10.1111/j.1462-2920.2007.01388.x.

[48] Zeng J, Bian YQ, Xing P et al. Macrophyte species drive the variation of bacterioplankton community composition in a shallow freshwater lake. Applied and Environmental Microbiology, 2012: 177-184. DOI: 10.1128/AEM.05117-11

[49] Tang XM, Chao JY, Gong Y et al. Spatiotemporal dynamics of bacterial community composition in large shallow eutrophic Lake Taihu: High overlap between free-living and particle-attached assemblages. Limnology and Oceanography, 2017, 62 : 1366-1382. DOI: 10.1002/lno.10502.

[50] Zhao DD. Cyanobacteria phosphatase gene diversity and its response to phosphorus [Dissertation]. Guangzhou: South China University of Technology, 2015. [ 赵丹丹. 蓝细菌磷酸酶基因多样性及其对磷素的响应 [ 学位论文]. 广州: 华南 理工大学, 2015 . 